\title{
REANALYSIS OF THE CHRONOLOGICAL DISCREPANCIES OBTAINED BY THE OLD AND MIDDLE KINGDOM MONUMENTS PROJECT
}

\author{
M W Dee ${ }^{1,2}$ • C Bronk Ramsey ${ }^{1} \cdot$ A J Shortland $^{3} \cdot$ T F G Higham $^{1}$ • J M Rowland ${ }^{1}$ \\ ABSTRACT. The most extensive chronometric study ever undertaken on Egyptian Dynastic sites was published in Radio- \\ carbon by Bonani et al. (2001). It comprised 269 radiocarbon measurements on monuments ranging from the 1st-12th dynas- \\ ties. However, many of the calibrated dates obtained were significantly offset from historical estimates. The greatest \\ discrepancies occurred in the 4th Dynasty where, paradoxically, the dating program had been most rigorous. For this period, \\ 158 measurements were made at 12 sites, with the majority of the dates being 200-300 yr older than expected. The 4th \\ Dynasty results were especially significant as they included some of the most important monuments in Egypt. In this paper, \\ the raw data from that study have been reanalyzed using the OxCal calibration program, making particular use of its new out- \\ lier detection functionality. This Bayesian approach has resulted in a new series of calibrations that show much closer agree- \\ ment with conventional chronological records.
}

\section{INTRODUCTION}

The challenge of establishing an accurate chronology for ancient Egypt is one that embodies the scale and antiquity of the civilization itself. The traditional approach is founded on the Egyptians' own King Lists on papyri and stone. One of the earliest attempts at compiling the full sequence was the Aegyptiaca, written by the historian Manetho in the 3rd century BC. Since that time, evidence from a wide range of archaeological and documentary sources has been used to add detail to the record (summarized by Kitchen 1991). The resulting chronology is now one of the most important historical references for the ancient Near East and Mediterranean regions. Within the Egyptological community itself, the timeline's familiar kingdoms and dynasties are almost universally employed. In fact, "dating" an item, in Egyptological terms, is generally achieved through classification by type and then placement within this historical sequence. This practice is not wholly satisfactory, however, for 2 main reasons. Firstly, the chronology is still characterized by missing and ambiguous information (Mellaart 1979; Kitchen 1991). Secondly, the lack of a robust frame of reference on the absolute timescale precludes comparisons where stylistic classification is not possible. This is most obviously the case for correlations with polities further afield, but also applies wherever the archaeological evidence is too fragmentary to be definitive. Most previous attempts at anchoring the chronology to the absolute timescale have involved tying a handful of records of the heliacal rising of Sothis (Sirius) to particular Egyptian civil calendar dates. However, in addition to their scarcity, such observations are also open to interpretation (Kitchen 1991; Krauss 2004). Hence, despite its general reliability and accuracy, the absolute positioning of the chronology continues to be controversial (Mellaart 1979; Kitchen 1991; Ward 1992; Krauss 2004; Bietak 2007).

Radiocarbon dating has provided absolute dates for Egyptian contexts for more than half a century. Unfortunately, the results have been neither consistent nor precise enough to disentangle conflicting historical evidence (Bruins and Mook 1989; Kitchen 1991; Shaw 2000; Manning 2006). Nonetheless, recent developments in the mathematical modeling of calibrated age ranges have revived interest in the applicability of ${ }^{14} \mathrm{C}$ dating to the problem.

In 1984, the American Research Center in Egypt began a ${ }^{14} \mathrm{C}$ dating project on Old Kingdom sites of the Giza plateau, sponsored by the Edgar Cayce Foundation. Funding was secured from David H Koch in 1995 for a second phase, entitled the Pyramids Radiocarbon Dating Project. The combined

\footnotetext{
${ }^{1}$ Research Laboratory for Archaeology, University of Oxford, Dyson Perrins Building, South Parks Road, Oxford OX1 3QY, United Kingdom.

${ }^{2}$ Corresponding author. Email: michael.dee@stx.ox.ac.uk.

${ }^{3}$ Centre for Archaeological and Forensic Analysis, Cranfield University, Shrivenham, Swindon SN6 8LA, United Kingdom.
} 
corpus of $269{ }^{14} \mathrm{C}$ dates was published in Radiocarbon (Bonani et al. 2001). The sites chosen ranged from the 1st-12th dynasties and included such important monuments as the Great Pyramid, the Sphinx, and the Step Pyramid. Indeed, the work remains the most comprehensive chronometric examination of the Egyptian chronology conducted to date.

The project samples consisted predominantly of charcoal (72\%), although grasses and twigs (19\%) as well as wood $(7 \%)$ were also dated. The charcoal came in the form of fragments extracted from the mortar found between stone blocks. The ancient Egyptians prepared their mortar by firing gypsum and limestone, with any leftover charcoal being added to the mix. The grasses and twigs were mostly removed from mud bricks and the wood from logs secured within structural walls. Every effort was made to obtain samples that were clearly inherent to the original structures themselves; that is, materials that could not have been incorporated at a later date. The pretreatment chemistry and ${ }^{14} \mathrm{C}$ measurements were carried out at 3 different laboratories: the original (1984) samples were sent to the Southern Methodist University, Dallas; while the follow-on work (1995) was split between the Desert Research Institute, Las Vegas, and the ETH laboratory in Zurich. All of the methodologies employed are detailed in the original publication (Bonani et al. 2001).

In total, 33 monuments were dated, with 30 included in the final set of calibrations. A copy of the chart of results from the original paper (Bonani et al. 2001) is shown here in Figure 1. Three patterns are immediately apparent: the ${ }^{14} \mathrm{C}$ dates are much less precise than the historical ones, they tend to be older, and the most consistently offset results are found in the 4th Dynasty (2613-2494 BC). Although these dates were only expressed as $68 \%$ probability ranges, the patterns are still evident when the more conservative $95 \%$ ranges are quoted. The disparities are certainly exacerbated, or at least appear so, by the plateau in the calibration curve in the mid-3rd millennium BC. As discussed by Manning (2006), ${ }^{14} \mathrm{C}$ determinations relating to this period that are only tens of ${ }^{14} \mathrm{C}$ yr too high can produce broad calibrations that extend back 300-400 yr with only the latter "edge" of the distribution being relevant. Nonetheless, the reason so many consistently high ${ }^{14} \mathrm{C}$ measurements were obtained warrants further attention.

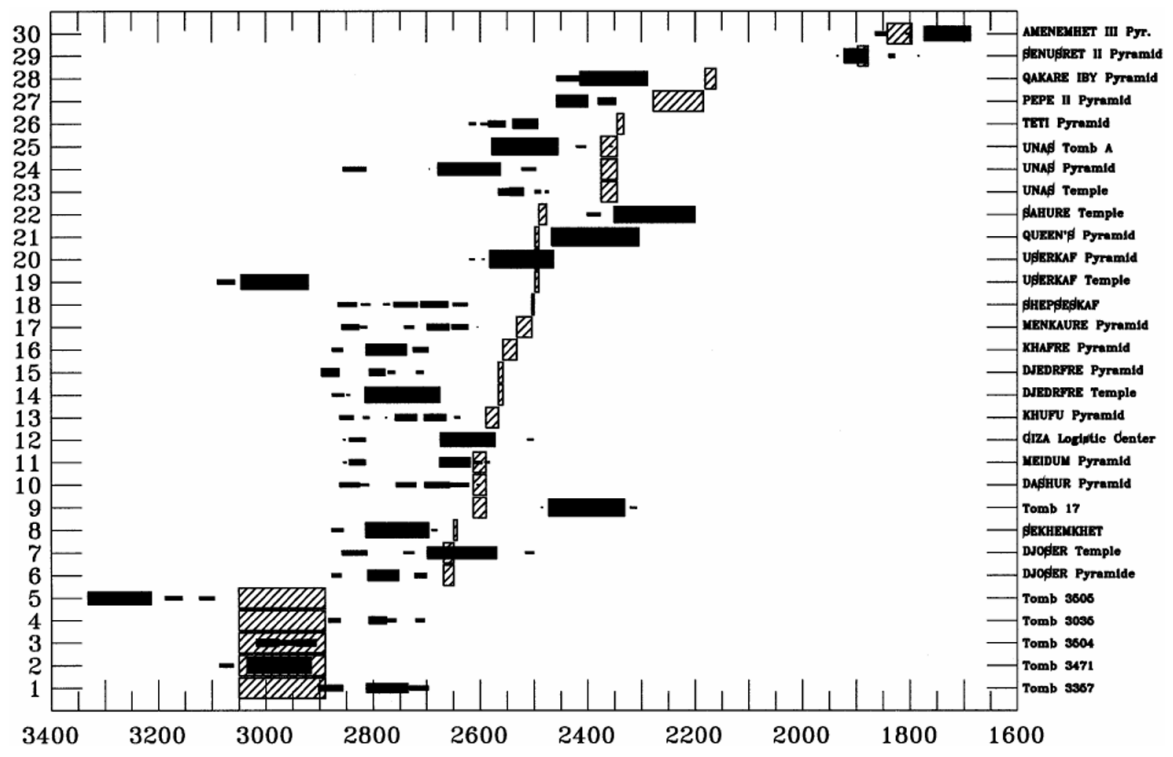

Figure 1 Comparison from Bonani et al. (2001) of the calibrated ${ }^{14} \mathrm{C}$ dates (black bars) with the historical chronology (hatched bars, Clayton 1994). The width of the black bars is proportional to the probability of finding the true age within the corresponding $1-\sigma(68 \%)$ range. 
The only results notably offset to younger ages were the 5th Dynasty (2494-2345 BC) sites of the Queen's pyramid of Userkaf (2494-2487 BC) at Saqqara and the mortuary temple and pyramid of Sahure (2487-2475 BC) at Abusir (Figure 1, monuments 21 and 22). However, the 5th (2494-2345 $\mathrm{BC})$ and 6th (2345-2181 BC) Dynasty sites clearly proved the most difficult to date, as the raw data showed a high a proportion of outliers. The most parsimonious explanation for this may be the misassociation of some samples with the original construction event. Many of the 33 sites selected for dating were actively reused for several centuries after their completion, and revisited throughout history. However, the 5th and 6th Dynasty structures are especially damaged and fragmentary, which would have made obtaining samples from the original phase of construction especially challenging. However, this explanation cannot be so readily applied to the dating discrepancies in the 4th Dynasty. The 12 structures that were dated from this period (of which only 10 were included in the final calibrations) accounted for almost $60 \%$ of the measurements obtained. In general, these monuments are clearly distinguishable and, despite having been constantly revisited down the centuries, the issue of young outliers did not arise. Therefore, only 2 explanations remain, either the monuments are genuinely older than previously thought or there is a problem with the reliability of the ${ }^{14} \mathrm{C}$ measurements.

This paper addresses the results obtained for the 4th Dynasty monuments. The fact such large numbers of dates were obtained for this dynasty and yet such distinct offsets were produced means these results were the most significant of the whole study. Fortuitously, however, it is precisely because the dating program was so intensive during the 4th Dynasty that a new statistical approach is able to be employed. The reanalysis presented here is based on chronological models that require greater numbers of dates than are available for the other dynasties of the study (see Table 1). The necessity to restrict the reanalysis to the 4th Dynasty was compounded by the comparatively low precision of many of the measurements (the overall average was $\pm 80{ }^{14} \mathrm{C}$ yr, $1 \sigma$ ). The new approach adopts a Bayesian methodology, specifically using the OxCal calibration program (Bronk Ramsey 1995, 2001). Bayesian modeling provides the means by which independent temporal information can be statistically combined with ${ }^{14} \mathrm{C}$ measurements (see Buck et al. 1991, 1992). In addition to enabling refinements to calibrations, the technique also allows probability densities to be produced for parameters that are often unable to be directly dated, such as the boundaries of phases (Buck et al. 1992; Bronk Ramsey 1995). However, the introduction of a priori information must be performed judiciously and conservatively, as misuse of the technique can lead to the deliberate biasing of results. In order to avoid this problem, the impact of all assumptions should be carefully examined using sensitivity testing and repeated model running. Ideally, the full model code should also be published.

Table $1{ }^{14} \mathrm{C}$ measurements by dynasty from the Old and Middle Kingdom Monuments Project. Only the 4th Dynasty offered sufficient numbers of dates for the production of high-precision Bayesian models.

\begin{tabular}{cc}
\hline Dynasty & $\mathrm{Nr}$ of ${ }^{14} \mathrm{C}$ measurements \\
\hline 1st & 12 \\
3rd & 24 \\
4th & 158 \\
5th & 43 \\
6th & 18 \\
8th & 1 \\
12th & 13 \\
Total & $\mathbf{2 6 9}$ \\
\hline
\end{tabular}


The overall objective of the reanalysis was to examine the underlying nature of the discrepancies observed in the 4th Dynasty. It is hoped that as further dates are produced the techniques employed here may be applied to other periods of Egyptian history.

\section{REANALYSIS RATIONALE: POINT AVERAGES VERSUS PHASE BOUNDARIES}

It is clear that the original ${ }^{14} \mathrm{C}$ determinations vary more appreciably than would be expected on the basis of counting statistics alone. The 46 individual dates for the Great Pyramid (Khufu, 2589-2566 $\mathrm{BC}$ ), for example, range from 3810 to $5020{ }^{14} \mathrm{C}$ yr BP. One of the aims of this reanalysis was to address why the dates were so widespread and how they should be combined. Bonani et al. (2001) chose to summarize the data by calibrating the weighted average of the measurements obtained for each monument. The approach presented here utilizes computer-based modeling.

${ }^{14} \mathrm{C}$ dating measures the time elapsed since the original organism ceased exchanging carbon with the atmosphere, so the ${ }^{14} \mathrm{C}$ determinations should all theoretically be older than the completion dates of the monuments, assuming the archaeological association of each sample can be assured. Furthermore, ${ }^{14} \mathrm{C}$ dates can accrue additional age by non-systematic effects. One such effect is "inbuilt age," which is defined as the difference in age between the death of the sample and the archaeological event being dated (McFadgen 1982; see also Waterbolk 1971). In the case of wood, it is the combination of growth age - the natural age of the tree - and storage age - the time between felling and use (McFadgen et al. 1994). In the original study, almost $80 \%$ of the dates were made on wood or charcoal. This number rises to $89 \%$ for the 158 dates from the 4th Dynasty. Samples taken for the project from inner tree rings would have certainly included an amount of growth age. Moreover, all ${ }^{14} \mathrm{C}$ measurements made on charcoal retain a bias to older ages which typically reflects the age of the wood from which the charcoal is derived. The indigenous trees of Egypt were generally not suitable for long timbers, so they must have primarily been used to produce the charcoal. The magnitude of the bias in the charcoal results remains unknown, and may have been significant even if the species used were not considerably long-lived. Secondly, the "life history" of the building materials is also essentially indeterminable. It is probable that some items were reclaimed from earlier constructions, or were stockpiled prior to use, thereby accruing further age offsets. In fact, Lehner et al. (1999) suggest that the scatter in the Old Kingdom (3rd-6th dynasties, 2686-2160 BC) dates supports the notion that the pyramid-builders were reusing their own settlement debris. Furthermore, Manning (2006) has proposed that intense pressure on resources during this period of unprecedented construction may have necessitated such recycling, and that a lesser degree of reuse may explain the more historically consistent results obtained by the original study for the Early Dynastic period (3000-2686 BC) and the 12th Dynasty (1985-1773 BC). Finally, the length of the construction program itself must be considered. It is reasonable to assume that some of the larger monuments took many years, perhaps even decades, to complete. Thus, even if inbuilt age was not a factor, it is most probable that the resources used on the first day of construction were much older than those used on the last. It is not thought likely that these factors would have biased every sample, but that a significant proportion would have been affected by one or more of them.

The question remains as to how the data should be summarized, given they clearly reflect a range of ${ }^{14} \mathrm{C}$ ages. It is obvious, however, that any averaging of the data sets would just provide an estimate of the mid-point of the measurements, which would continue to be non-systematically offset to older ages by the factors listed above. One potentially attractive avenue is to use Bayesian modeling to estimate a nominated date or event. For this analysis, the completion date of construction was deemed the most suitable parameter. Unlike the beginning or mid-points, this boundary was more likely to be static and unaffected by inbuilt age. In real terms, it should represent the point at which short-lived, non-stockpiled or recycled material was included on the last day of construction. OxCal 
automatically generates a probability distribution for this parameter. An example of the procedure, using the dates from the Pyramid of Djedefre, is given in Figure 2. The individual ${ }^{14} \mathrm{C}$ dates for this monument (Figure 2a) are clearly not normally distributed about a specific date or short span of dates. Instead, they indicate the variation of the ages of the materials used in construction (over $400{ }^{14} \mathrm{C} \mathrm{yr}$ ). By treating the results as a phase, the most probable youngest date can be modeled (Figure $2 b$ ). If even greater numbers of dates had been obtained, it is likely the distribution of material ages would have exhibited an exponential decrease back in time from the completion date. If this were true, the difference between the completion date and the average date would approximate the time constant of the material ages; that is, the average value of the inbuilt age.

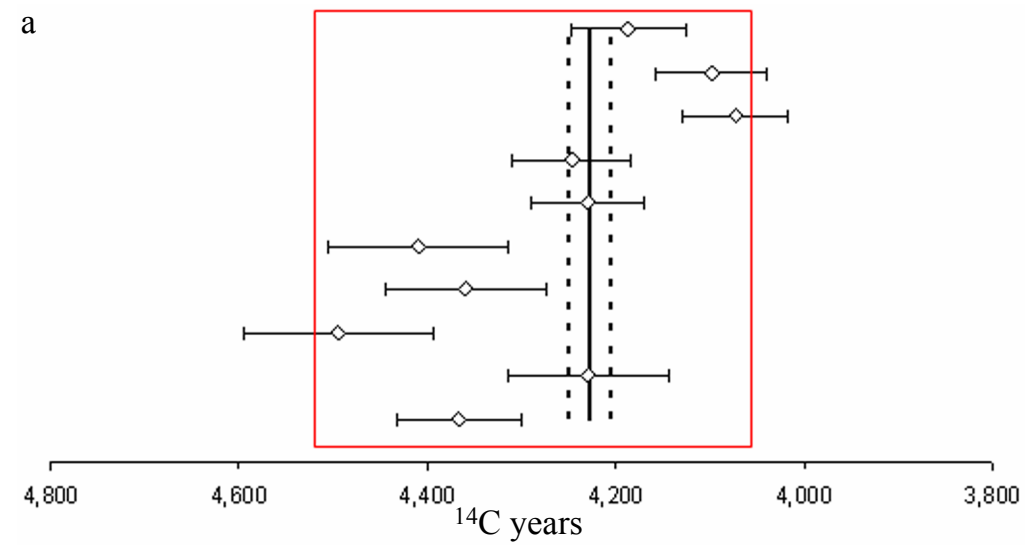

b

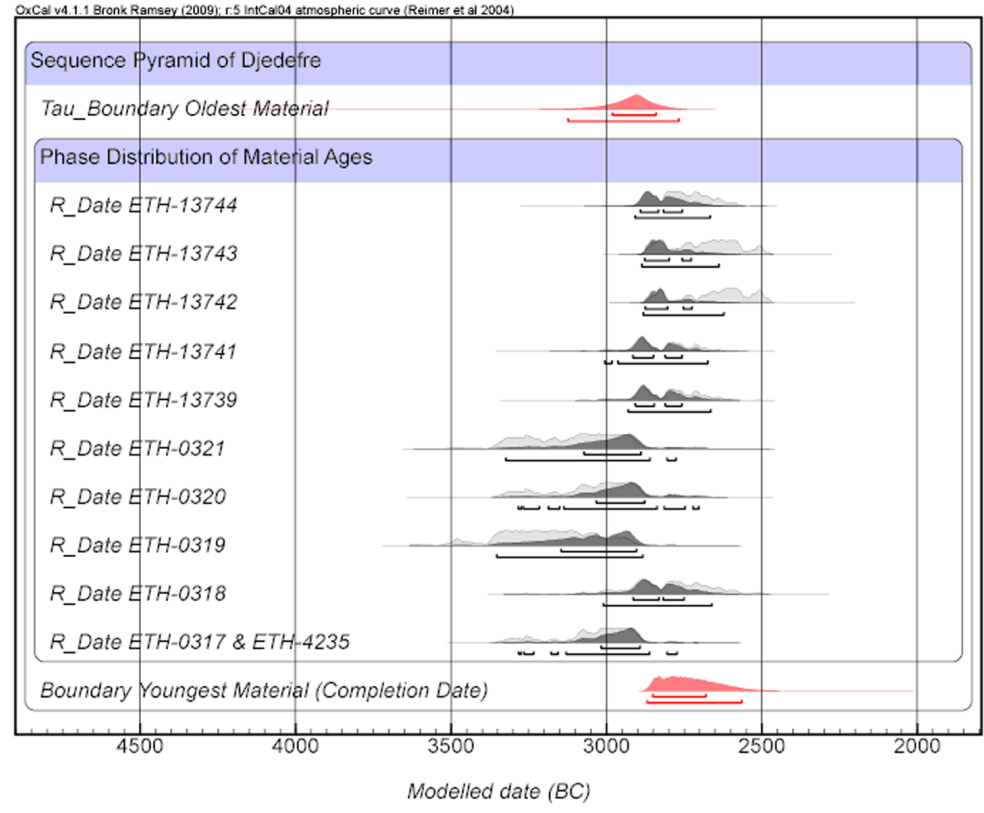

Figure 2 a) The individual measurements (1- $\sigma$ errors) from the pyramid of Djedefre and the resultant weighted average (heavy line) with its $1-\sigma$ errors (dashed line). The box around the data approximates the range of material ages, the end boundary of which is being modeled in this reanalysis. b) The modeled calibrations. The $1-\sigma(68 \%)$ and $2-\sigma(95 \%)$ ranges are given by the horizontal brackets beneath the probability densities. The end boundary of the phase is the given at the bottom of the figure. 


\section{MODEL SPECIFICATIONS}

One of the central objectives of the revision presented here was to retain as many of the original dates as possible. However, those that could not be ascribed to a given king's reign were omitted. Minimizing this uncertainty was imperative, because the King List order was to be used as prior information within the modeling process. Nonetheless, the only site affected by this criterion was the Royal Production Centre ( 8 dates), as its use traversed several reigns and the allocation of structures to individual kings was problematic.

The chronological models were built using the OxCal calibration program. Extensive use was made of the software's new outlier detection functionality. This tool was developed by Bronk Ramsey (2009) building on work by Christen $(1994,2003)$. Its purpose is to identify and reduce the impact of inconsistent results on the outputs of the model. The first requirement of the outlier detection procedure was to "tag" each date with a prior probability that reflected the likelihood it was an errant result. To maintain as much objectivity as possible, this outlier assessment did not involve any recourse to the original ${ }^{14} \mathrm{C}$ measurement. In fact, the probability was eventually set to the same value for each date. By adopting this principle, the identification of inconsistent dates would be left solely to the Markov chain Monte Carlo (MCMC) algorithm itself. Initial outlier probabilities ranging from $2-10 \%$ were trialled, with the outputs remaining essentially unchanged. Eventually, however, a uniform prior of 5\% was settled upon, as those models with lower starting probabilities at times failed to converge.

Running the outlier detection tool is straightforward. The OxCal program iteratively samples from the initial calibrations, as previously, but in the Outlier mode it also continually determines the compatibility of each measurement with its associated phase members and the sequence as a whole. Dates that show a lack of consistency are gradually marginalized from the final models. Upon completion, the program provides posterior outlier probabilities for every date. Clearly, the ability of the application to downweigh and ultimately eliminate errant results is still limited by the proportion and clustering of the dates within each phase. A detailed description of the relevant calculations involved is given by Bronk Ramsey (2009).

A continuous chronological model was constructed for the 4th Dynasty. The boundaries of the sequence extended from 500 calendar yr before the historical reign of Sneferu (2613-2589 BC) to $500 \mathrm{yr}$ after the reign of Shepseskaf (2503-2498 BC). These conservative limitations were added to improve the convergence times of the models. The data sets for each monument were treated as phases and the MCMC program was then used to estimate the end boundaries of these phases, which represented the completion dates of the monuments. In order to limit the range of potential solutions, the known King List order was incorporated as a priori information. However, this information represented the only parameter introduced to the model from conventional records. Where more than 1 monument was ascribed to the same king, the chronological order of the structures was not specified.

Tau boundaries were used at the beginning of each phase and uniform boundaries at the end. The tau boundary reflects an exponential increase in probability with time allowing for the fact that most samples were likely to have been collected towards the end of each phase. This technique was employed to counteract the effect of inbuilt age and focus the iterative method on the latter portion of the individual calibrations. However, the effect of the tau boundaries was very minor, as no major change to the outputs of the model was observed when solely uniform boundaries were employed.

To optimize parametric independence, ${ }^{14} \mathrm{C}$ dates were only combined when it was explicit in the original text that they had arisen from duplicate measurements on the same sample. The R_Combine function in $\mathrm{OxCal}$ achieves this automatically, by way of weighted averages, though an extra uncer- 
tainty of $8{ }^{14} \mathrm{C}$ yr (maximum annual ${ }^{14} \mathrm{C}$ variation) was added to avoid being inadvertently precise with respect to the calibration curve. In one instance, measurements from the same sample did not pass the chi-square agreement test. In this case, the date which gave the highest $t$ statistic was removed, as per Wilson and Ward (1981). From the original 158 measurements, a total of 133 dates remained after the Royal Production Centre dates had been excluded and the same-sample measurements had been combined. The full code for the model produced by this study is available in an Appendix to the online version of the article.

\section{RESULTS AND DISCUSSION}

The results obtained by this reanalysis showed much closer agreement with historical records than those of Bonani et al. (2001). The resultant $68 \%$ and $95 \%$ calibrated age ranges are shown in Table 2 and plotted in Figure 3. In general, the modeling process produced younger and more precise calibrated age ranges. This variation can easily be accounted for by considering the dissimilar treatments of the data and the differing objectives of the 2 studies. As mentioned above, the results reported here are estimates for the completion dates of the monuments. They do not represent averages of the different sets of ${ }^{14} \mathrm{C}$ measurements. Further, as they relate to the completion dates of the structures, they are categorically not intended to reflect the regnal dates for individual kings. In fact, the calibrations are centered at slightly younger ages than the chronology given in Shaw (2000). Assuming that such historical dates are not slightly too old, a possible interpretation might be that some of the structures were completed in the last years of the king's reign or within the reign of his successor (see Lehner et al. 1999; Werner 2002).

Table 2 The $68 \%$ and $95 \%$ probability ranges for the completion dates of the monuments. The historical reigns for the kings to whom the monuments are dedicated are given on the right. ${ }^{\mathrm{a}}$

\begin{tabular}{|c|c|c|c|c|c|c|c|c|c|}
\hline \multirow[b]{2}{*}{ King } & \multirow[b]{2}{*}{ Monument } & \multirow[b]{2}{*}{ Location } & \multicolumn{3}{|c|}{$\begin{array}{c}\text { Completion } \\
\text { date } \\
\text { (cal BC, 68\%) }\end{array}$} & \multicolumn{2}{|c|}{$\begin{array}{c}\text { Completion } \\
\text { date } \\
\text { (cal BC, 95\%) }\end{array}$} & \multicolumn{2}{|c|}{$\begin{array}{l}\text { King's reigns } \\
\text { from historical } \\
\text { chronology }(\mathrm{BC})\end{array}$} \\
\hline & & & $\begin{array}{l}\mathrm{Nr} \text { of } \\
\text { dates }\end{array}$ & From & To & From & To & From & To \\
\hline \multirow[t]{3}{*}{ Sneferu } & Pyramid & Meydum & 7 & 2609 & 2533 & 2692 & 2500 & 2613 & 2589 \\
\hline & Bent Pyramid & Dahshur & 2 & 2618 & 2530 & 2721 & 2500 & 2613 & 2589 \\
\hline & Tomb 17 & Meydum & 3 & 2594 & 2521 & 2716 & 2496 & 2613 & 2589 \\
\hline Khufu & Great Pyramid & Giza & 40 & 2559 & 2518 & 2620 & 2484 & 2589 & 2566 \\
\hline \multirow{2}{*}{ Djedefre } & Pyramid & Abu Roash & 10 & 2550 & 2497 & 2596 & 2461 & 2566 & 2558 \\
\hline & Pyramid Temple & Abu Roash & 4 & 2548 & 2494 & 2589 & 2458 & 2566 & 2558 \\
\hline \multirow[t]{2}{*}{ Khafre } & Pyramid & Giza & 24 & 2527 & 2463 & 2559 & 2433 & 2558 & 2532 \\
\hline & Sphinx & Giza & 1 & 2525 & 2422 & 2558 & 2361 & 2558 & 2532 \\
\hline Menkaure & Pyramid & Giza & 30 & 2456 & 2370 & 2553 & 2251 & 2532 & 2503 \\
\hline \multirow[t]{2}{*}{ Shepseskaf } & Mastaba el-Faraoun & South Saqqara & 5 & 2538 & 2228 & 2550 & 2143 & 2503 & 2498 \\
\hline & Mortuary Temple & South Saqqara & 7 & 2532 & 2322 & 2550 & 2219 & 2503 & 2498 \\
\hline
\end{tabular}

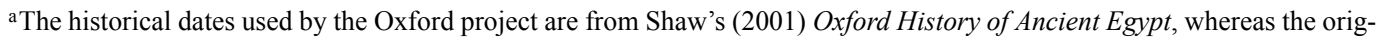
inal project used Clayton (1994). For the period concerned, the 2 chronologies are identical.

By grouping the data into phases and producing estimates for the end boundaries, it is self-evident that the calibrations shift to younger ages. Nonetheless, the effect was at times considerable, clearly reflecting the variable nature of the original results. In some cases, the same data produced end boundary estimates that did not even overlap the distribution obtained by calibrating the average. Furthermore, any initial shifts were often enlarged when the end boundary calibrations were constrained to meet the order of the King Lists. The full effect of the Bayesian approach on the suite of dates from the pyramid of Khufu is shown in Figure 4. 


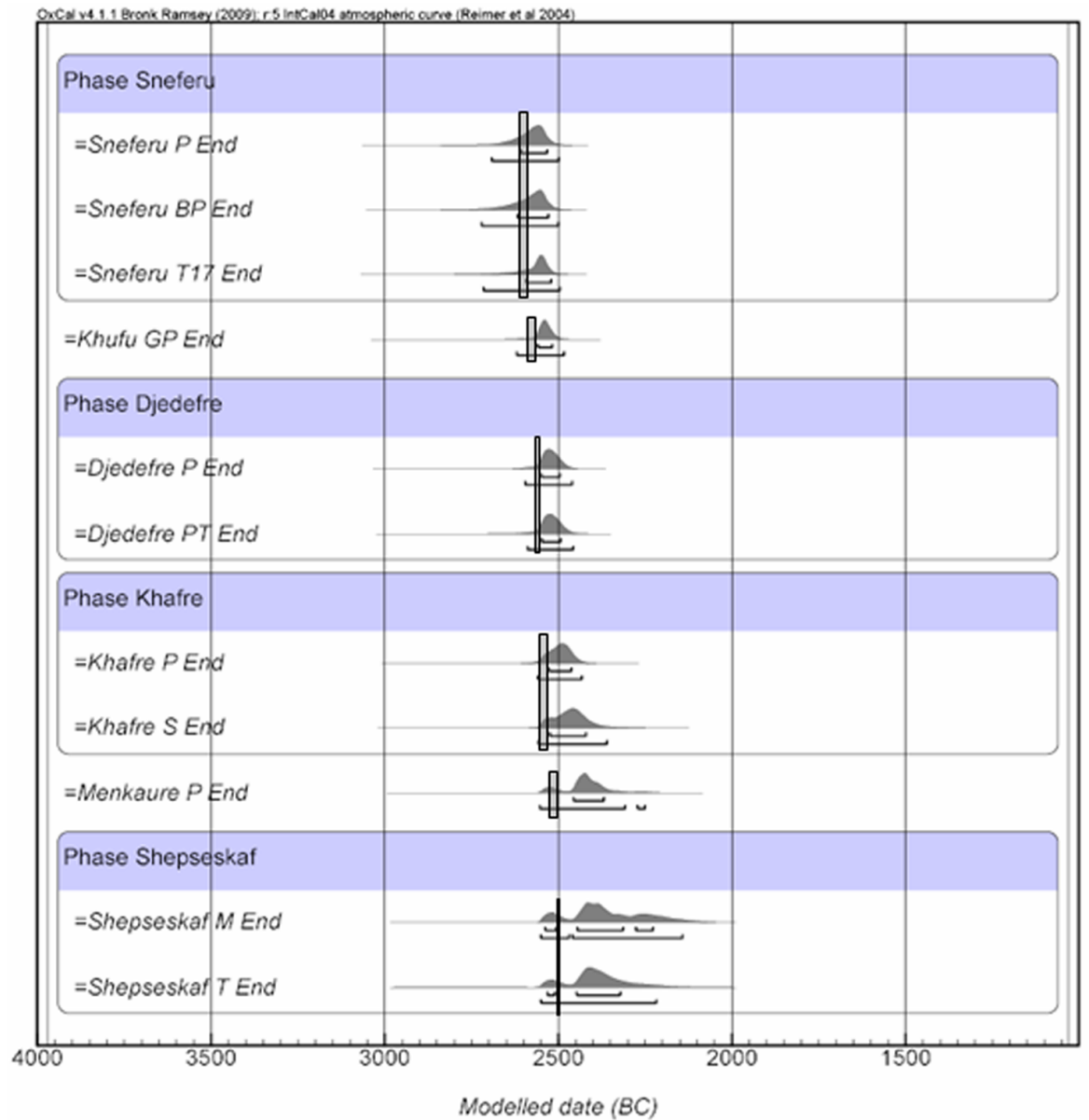

Figure 3 The calibrated age ranges for the completion dates of the 4 th Dynasty structures. The $68 \%$ and $95 \%$ ranges are shown beneath the probability densities by the horizontal brackets. The historical reigns for each king are indicated by the vertical bars.

By estimating the endpoints of construction it was hoped that the unquantifiable inbuilt age element could be minimized. The younger, more precise results presented here are consistent with this reasoning. However, the archaeological explanation of the shifts observed, as provided above, remains a response to the patterns produced solely by the numerical outputs of the computational process itself. That is, the calibrations obtained are independent of the correctness of this interpretation.

A further aspect of the results that is worth highlighting is the trend towards higher precision with increased numbers of dates. The $95 \%$ probability ranges achieved for the most populated phases were especially precise (Khafre's pyramid, 126 yr; Djedefre's pyramid, 135 yr; the Great Pyramid, $136 \mathrm{yr}$ ). Though this feature is intuitive, such marked improvements cannot be replicated by the calibration of averages, as the outcomes remain too dependent on the shape of the calibration curve. Moreover, these high-precision dates were also amongst the most consistent with historical reasoning, implying that further accuracy may only be dependent on the acquisition of more data. The Shepseskaf results, conversely, suffered from fewer dates and the absence of the constraining effect of later monuments. 

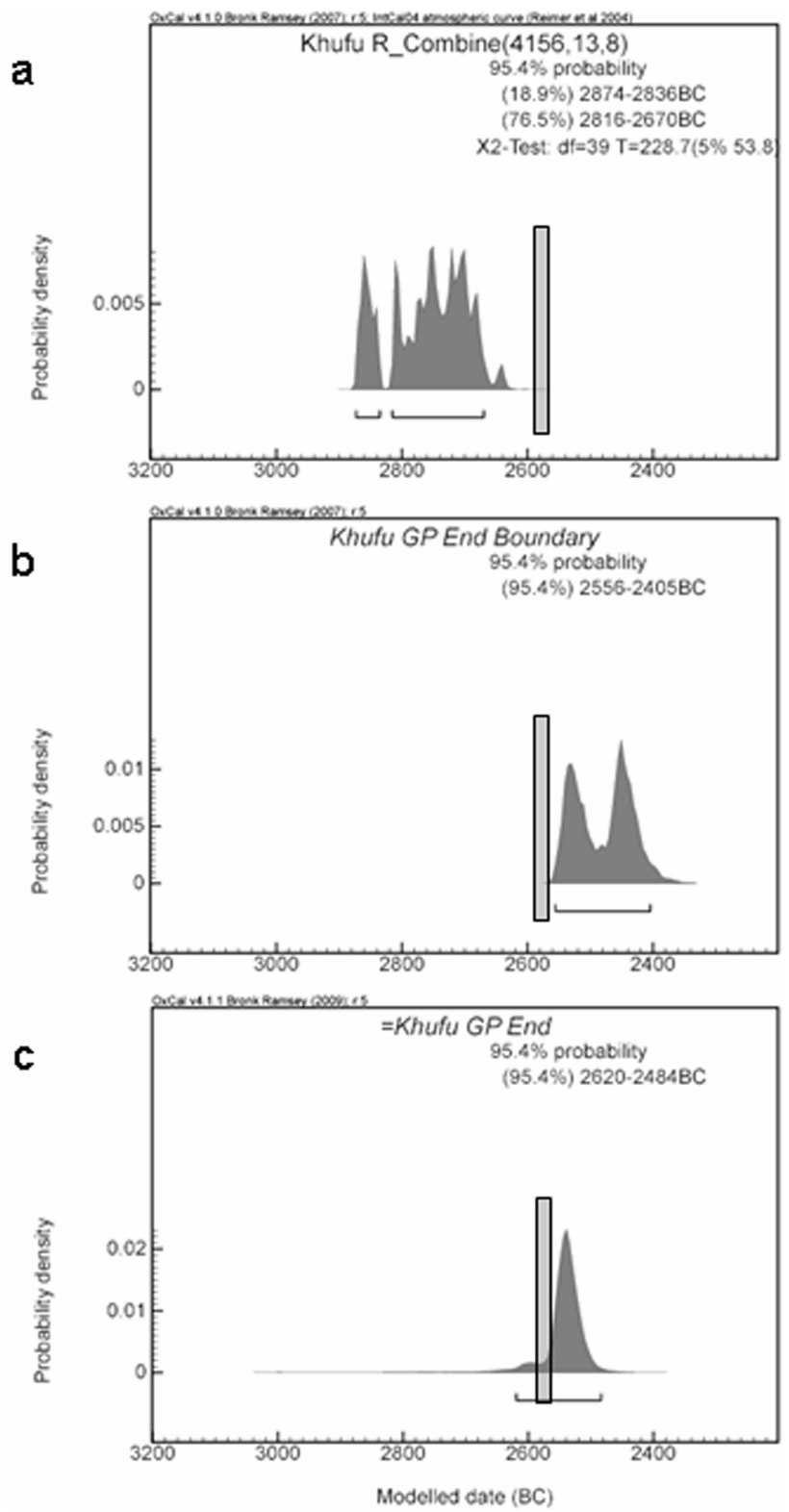

Figure 4 Comparison of the $95 \%$ calibrated age ranges for the Pyramid of Khufu. The calibrated date for the weighted average of the data (4a). The end boundary estimate from the same data set (4b). The end boundary when King List order is imposed on the model (4c). The historical reign of Khufu (2589-2566 BC) is indicated by the vertical bar.

\section{CONCLUSIONS}

The work of Bonani et al. (2001) remains a seminal contribution to our understanding of the chronology of Egypt, and the problems associated with ${ }^{14} \mathrm{C}$ dating this context. Although the raw measurements have previously been considered incompatible with historical records, particularly 
throughout the 4th Dynasty, the reanalysis offered here has challenged this interpretation. By not eliminating any results based on the ${ }^{14} \mathrm{C}$ measurement obtained, a level of objectivity was maintained throughout the modeling program. The issue of variability in the data sets is indisputable and is almost certainly caused by archaeological and taphonomic variables rather than inherent problems with the ${ }^{14} \mathrm{C}$ method itself. However, by focusing on the lower end of these age ranges, robust calibrations were achieved for the completion dates of all the monuments that could be assigned to an individual king. The most tightly constrained and data-rich sites produced the most refined calibrations, but the entire sequence exhibited excellent agreement with the Egyptian historical chronology.

\section{ACKNOWLEDGMENTS}

This work is part of the wider Egyptian Chronology project at the University of Oxford funded by the Leverhulme Trust. We are indebted to M Lehner and J Nolan from the Old and Middle Kingdom Monument's project for their generosity in providing access to their field notes. We would also like to acknowledge the institution to which they both are affiliated, the Ancient Egypt Research Associates (AERA).

\section{REFERENCES}

Bietak M. 2007. Introduction: High and Low Chronology. In: Bietak M, Hoflmayer F, editors. Synchronisation of Civilizations in the Eastern Mediterranean in the Second Millenium B.C. III. Vienna: Austrian Academy of Sciences Press. p 13-23.

Bonani G, Hass H, Hawass Z, Lehner M, Nakhla S, Nolan J, Wenke R, Wölfli W. 2001. Radiocarbon dates of Old and Middle Kingdom monuments in Egypt. Radiocarbon 43(3):1297-320.

Bronk Ramsey C. 1995. Radiocarbon calibration and analysis of stratigraphy: the OxCal program. Radiocarbon 37(2):425-30.

Bronk Ramsey C. 2001. Development of the radiocarbon calibration program. Radiocarbon 43(2A):355-63.

Bronk Ramsey C. 2009. Dealing with outliers and offsets in radiocarbon dating. Radiocarbon, this issue.

Bruins HJ, Mook WG. 1989. The need for a calibrated radiocarbon chronology of Near Eastern archaeology. Radiocarbon 31(3):1019-29.

Buck CE, Kenworthy JB, Litton CD, Smith AFM. 1991. Combining archaeological and radiocarbon information: a Bayesian approach to calibration. Antiquity 65(249):808-21.

Buck CE, Litton CD, Smith AFM. 1992. Calibration of radiocarbon results pertaining to related archaeological events. Journal of Archaeological Science 19(5): 497-512.

Christen JA. 1994. Summarizing a set of radiocarbon determinations: a robust approach. Applied StatisticsJournal of the Royal Statistical Society Series C 43(3): 489-503.

Christen JA. 2003. Bwigg: an internet facility for Bayesian radiocarbon wiggle matching. Internet Archaeology 7. Available at http:/intarch.ac.uk/journal/issue13/ christe_index.html.
Clayton PA. 1994. Chronicle of the Pharaohs. London: Thames and Hudson.

Kitchen KA. 1991. The chronology of ancient Egypt. World Archaeology 23(2):201-8.

Krauss R. 2004. Manetho's Twelfth Dynasty and the standard chronology. The Society for the Study of Egyptian Antiquities 29.

Lehner M, Nakhla S, Hawass Z, Bonani G, Wenke R, Nolan J, Wetterstrom W. 1999. Dating the pyramids. Archaeology 52(5):26-33.

Manning SW. 2006. Radiocarbon dating and Egyptian chronology. In: Hornung E, Krauss R, Warburton DA, editors. Ancient Egyptian Chronology. Leiden: Brill. p 327-55.

McFadgen BG. 1982. Dating New Zealand archaeology by radiocarbon. New Zealand Journal of Science 25: 379-92.

McFadgen BG, Knox FB, Cole TRL. 1994. Radiocarbon calibration curve variations and their implications for the interpretation of New Zealand Prehistory. Radiocarbon 36(2):221-36.

Mellaart J. 1979. Egyptian and Near Eastern chronology: a dilemma? Antiquity 53(207):6-20.

Shaw I. 2000. The Oxford History of Ancient Egypt. Oxford: Oxford University Press.

Ward WA. 1992. The present status of the Egyptian chronology. Bulletin of the American Schools of Oriental Research 288:53-66.

Waterbolk HT. 1971. Working with radiocarbon dates. Proceedings of the Prehistoric Society 37:15-33.

Werner M. 2002. The Pyramids. London: Grove Press.

Wilson SR, Ward GK. 1981. Evaluation and clustering of radiocarbon age determinations: procedures and paradigms. Archaeometry 23(1):19-39. 


\section{Appendix: OxCal Model Code}

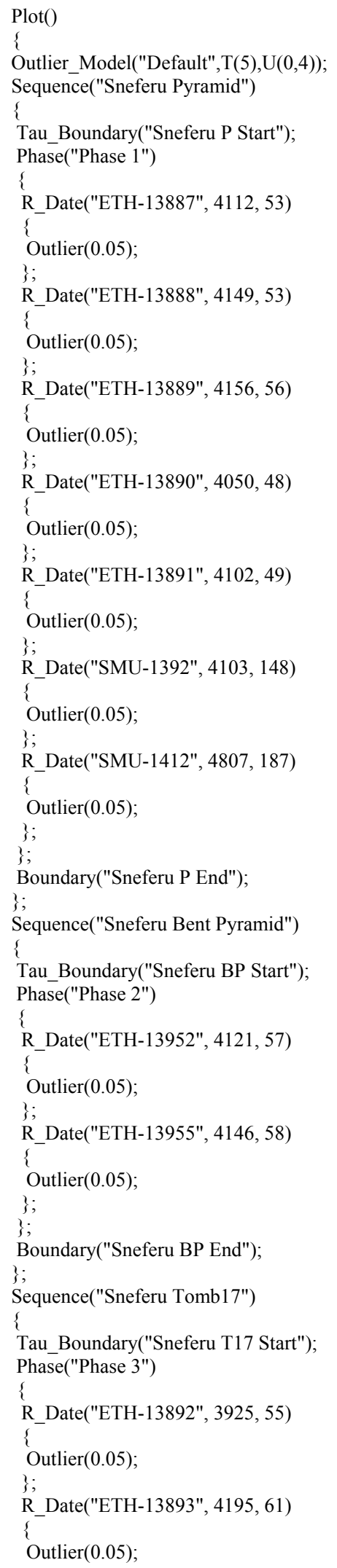




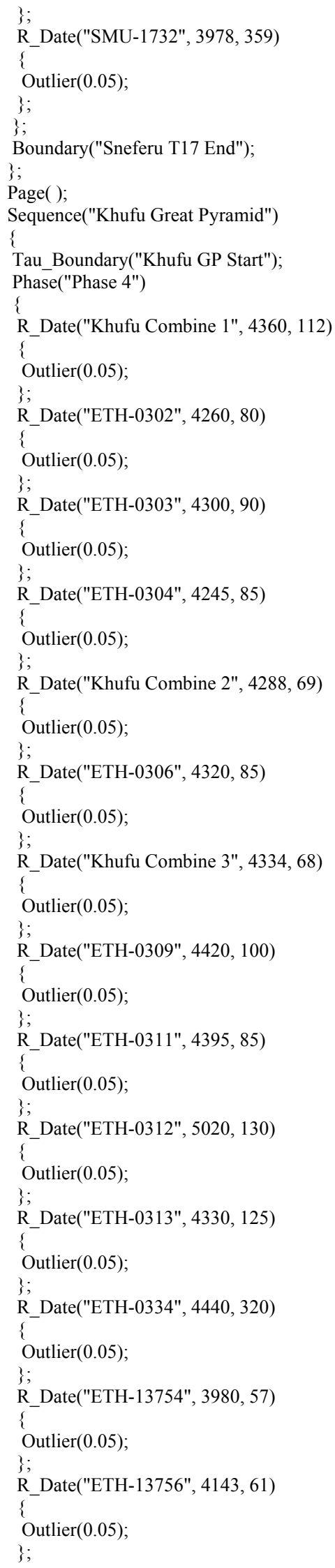




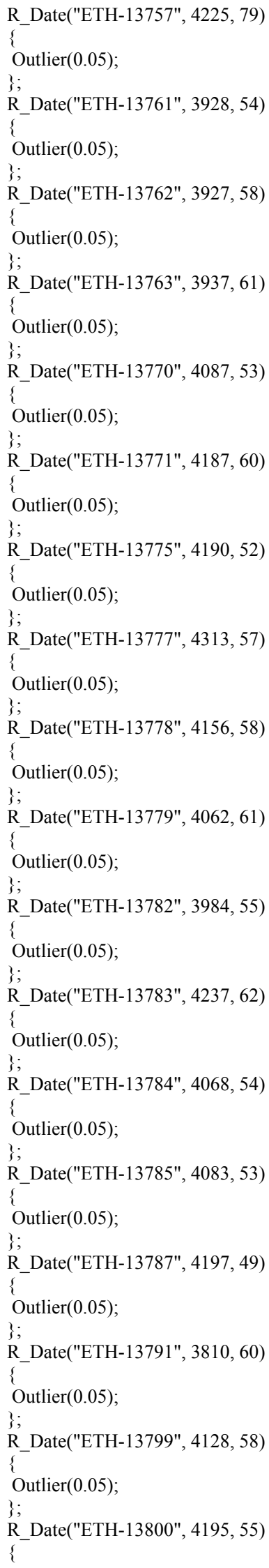




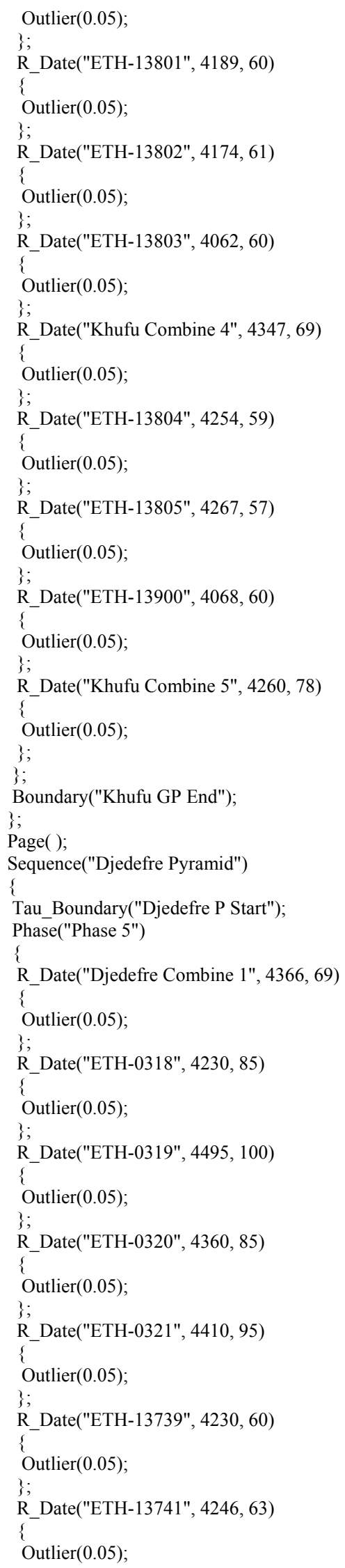




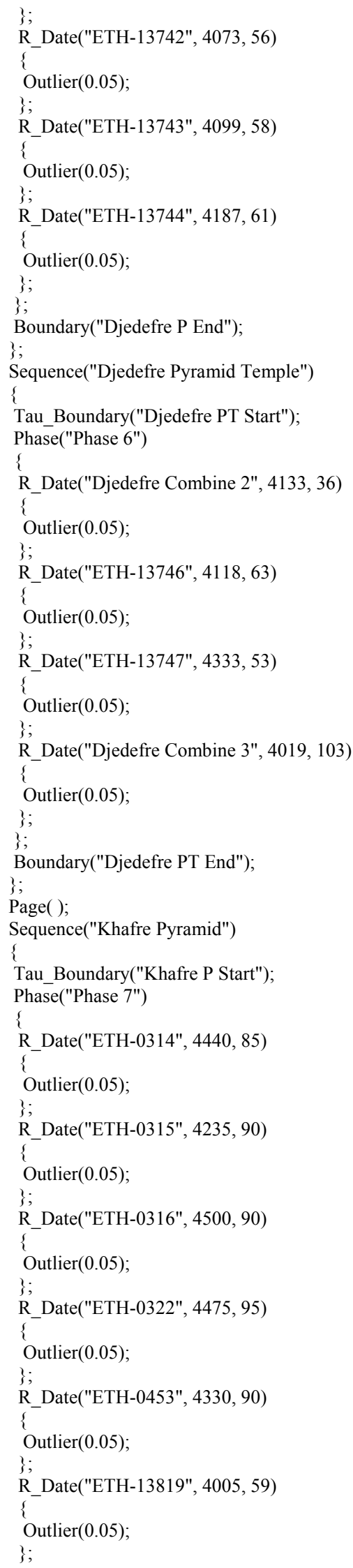




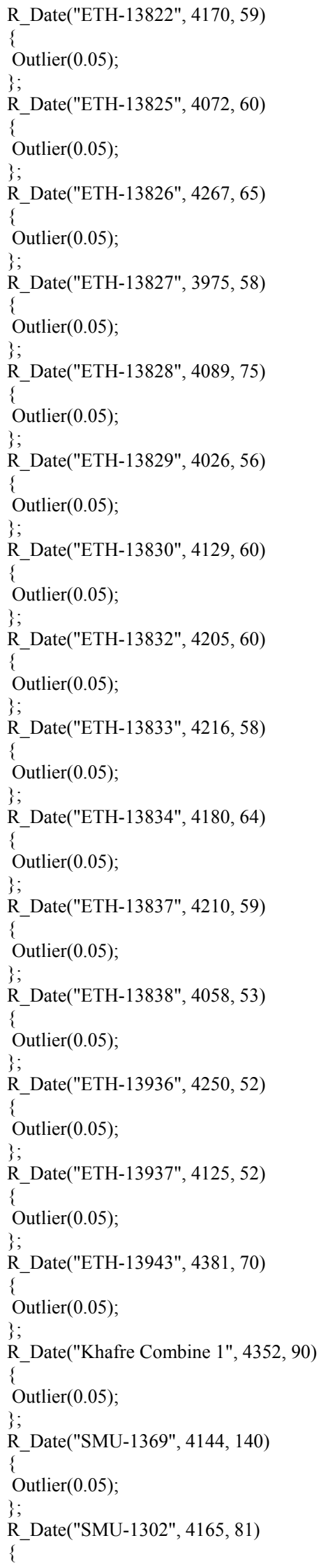




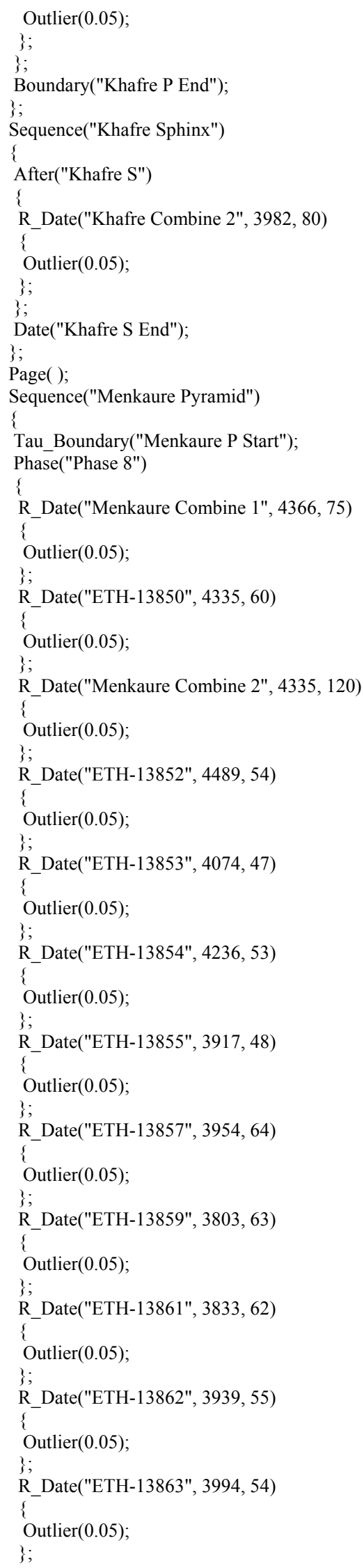




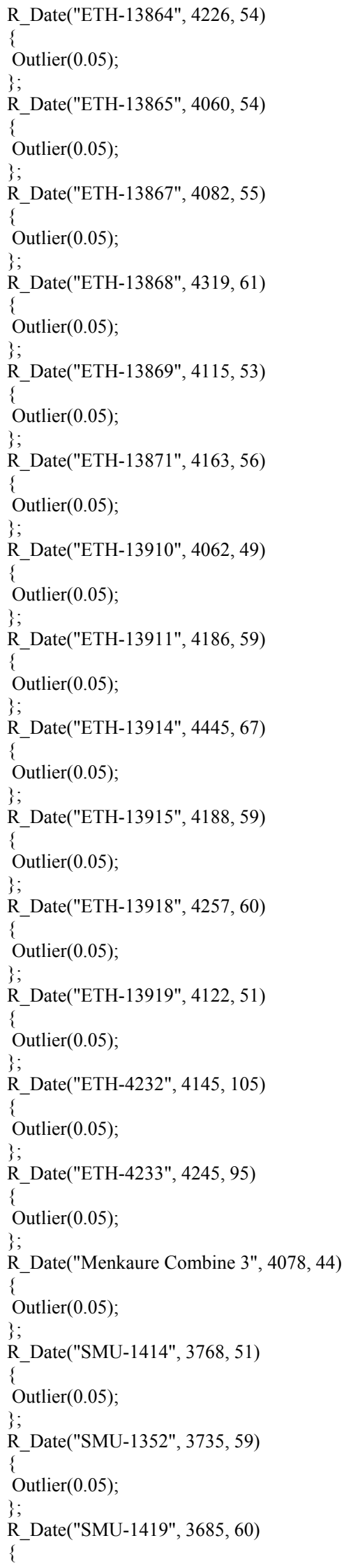




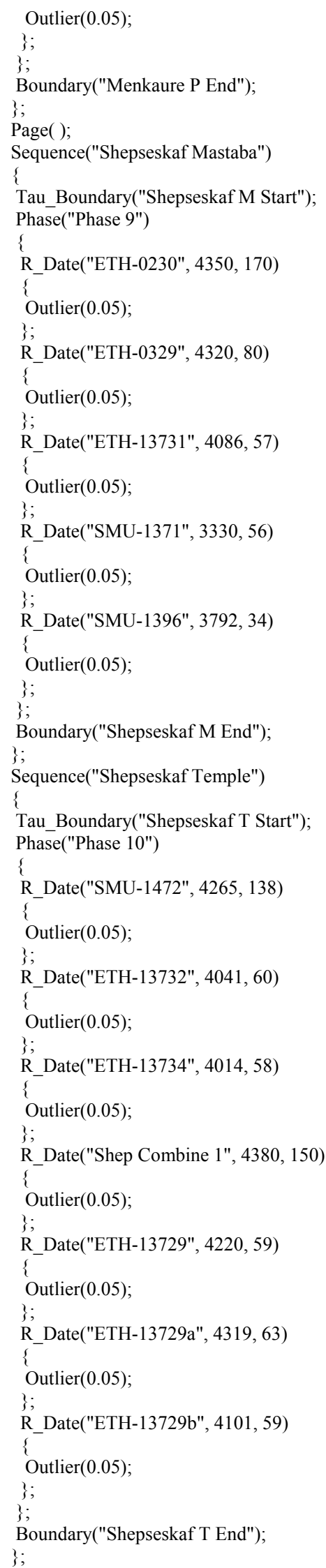


Page( );

Sequence("4th Dynasty")

\{

Boundary("Start 4th Dynasty", U(-3113, -2113));

Page( );

Phase("Sneferu")

\{

Date("=Sneferu P End");

Date("=Sneferu BP End");

Date("=Sneferu T17 End");

\};

Date("=Khufu GP End");

Phase("Djedefre")

\{

Date("=Djedefre P End");

Date("=Djedefre PT End");

;

Phase("Khafre")

\{

Date("=Khafre P End");

Date("=Khafre S End");

;

Date("=Menkaure P End");

Phase("Shepseskaf")

Date("=Shepseskaf M End");

Date("=Shepseskaf T End");

;

Page( );

Boundary("End 4th Dynasty", U(-2998, -1998));

;

; 